\title{
Dynamic respiratory mechanics and exertional dyspnoea in pulmonary arterial hypertension
}

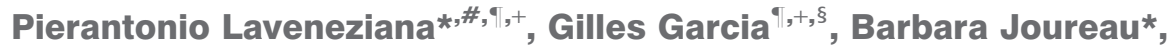 \\ Fadia Nicolas-Jilwan ${ }^{\uparrow, \S}$, Toufik Brahimi ${ }^{\uparrow, \S}$, Louis Laviolette*, Olivier Sitbon ${ }^{\uparrow,+, f,}$ \\ Gérald Simonneau ${ }^{\uparrow,+, f}$, Marc Humbert ${ }^{\uparrow,+, f, * *}$ and Thomas Similowski ${ }^{*, \#, * *}$
}

ABSTRACT: Patients with pulmonary arterial hypertension (PAH) may exhibit reduced expiratory flows at low lung volumes, which could promote exercise-induced dynamic hyperinflation (DH). This study aimed to examine the impact of a potential exercise-related DH on the intensity of dyspnoea in patients with PAH undergoing symptom-limited incremental cardiopulmonary cycle exercise testing (CPET).

25 young (aged mean \pm SD $38 \pm 12$ yrs) nonsmoking PAH patients with no evidence of spirometric obstruction and 10 age-matched nonsmoking healthy subjects performed CPET to the limit of tolerance. Ventilatory pattern, operating lung volumes (derived from inspiratory capacity (IC) measurements) and dyspnoea intensity (Borg scale) were assessed throughout CPET.

IC decreased (i.e. DH) progressively throughout CPET in PAH patients (average $0.15 \mathrm{~L}$ ), whereas it increased in all the healthy subjects $(0.45 \mathrm{~L})$. Among PAH patients, $15(60 \%)$ exhibited a decrease in IC throughout exercise (average $0.50 \mathrm{~L}$ ), whereas in the remaining $10(40 \%)$ patients IC increased (average $0.36 \mathrm{~L}$ ). Dyspnoea intensity and ventilation were greater in PAH patients than in controls at any stage of CPET, whereas inspiratory reserve volume was lower.

We conclude that $\mathrm{DH}$-induced mechanical constraints and excessive ventilatory demand occurred in these young nonsmoking PAH patients with no spirometric obstruction and was associated with exertional dyspnoea.

KEYWORDS: Dynamic lung hyperinflation, dyspnoea, exercise, pulmonary arterial hypertension, ventilatory mechanics

E xertional dyspnoea is the most frequent complaint for which patients with pulmonary arterial hypertension (PAH) seek medical attention. It progresses relentlessly as the disease advances, contributing significantly to a reduced quality of life [1]. Previous studies on the mechanisms of exertional dyspnoea in PAH have largely and mostly focused on the cardiovascular determinants of respiratory discomfort [2-4]. However, respiratory mechanics abnormalities could contribute to and aggravate exertional dyspnoea in these patients. For instance, PAH patients may exhibit reduced expiratory flows at low lung volumes at spirometry (namely instantaneous forced expiratory flows measured after $50 \%$ and $75 \%$ of the forced vital capacity (FVC) has been exhaled (FEF50\% and FEF75\%, respectively) lower than predicted), despite a preserved forced expiratory volume in $1 \mathrm{~s}$ (FEV1)/FVC ratio
[5-7]. Several studies have shown that such a finding could be common in certain PAH cohorts [5-7], have related it to incidental descriptions of airway wall thickening with lymphocytic infiltration in PAH [5] and have proposed several other speculative explanatory mechanisms, either biological or mechanical $[6,7]$. Whatever their cause, reduced expiratory flows at low lung volumes imply that the operating tidal volume $(V \mathrm{~T})$ range becomes closer than normally to residual volume (RV) mostly through an increase in RV (elevated $\mathrm{RV} /$ total lung capacity (TLC) ratio). The reduced difference between forced and tidal expiratory flows promotes dynamic lung hyperinflation $(\mathrm{DH}$, a progressive increase in end-expiratory lung volume (EELV)) under conditions of increased ventilatory demand. DH increases the mechanical inspiratory load that the respiratory muscles must overcome to produce minute ventilation $\left(V^{\prime} \mathrm{E}\right)$,

\section{AFFILIATIONS}

*Univ Paris 06, Equipe de Recherche ER 10 UPMC, Laboratoire de PhysioPathologie Respiratoire, Faculté de Médecine Pierre et Marie Curie (site Pitié-Salpêtrière),

\#Assistance Publique-Hôpitaux de Paris, Groupe Hospitalier PitiéSalpêtrière, Service de Pneumologie et Réanimation Médicale, Paris,

"Univ Paris-Sud, Faculté de

médecine, Le Kremlin-Bicêtre, +INSERM U999, Centre Chirurgical Marie Lannelongue, Le PlessisRobinson,

${ }^{\S}$ Assistance Publique Hôpitaux de Paris, Service de Physiologie, Hôpital Antoine Béclère, and

${ }^{\dagger}$ Assistance Publique Hôpitaux de Paris, Service de Pneumologie et Réanimation Respiratoire, Centre National de Référence de

l'Hypertension Pulmonaire Sévère, Hôpital Antoine Béclère, Clamart, France.

**These authors contributed equally.

CORRESPONDENCE

P. Laveneziana, Université Paris 06 , ER 10 UPMC, Laboratoire de PhysioPathologie Respiratoire, Département de Physiologie, Faculté de Médecine Pierre et Marie Curie, Site PitiéSalpêtrière, 91 Boulevard de l'Hôpital, 75013, Paris, France E-mail: pier_lav@yahoo.it

\section{Received:}

Dec 202011

Accepted after revision:

June 092012

First published online:

July 122012 
places the diaphragm at a mechanical disadvantage, and reduces the ability of $V$ T to expand appropriately during exercise, thus imposing "restrictive" mechanics [8, 9]. Dyspnoea ensues, as clearly shown in flow-limited patients with chronic obstructive pulmonary disease (COPD) and chronic heart failure (CHF) during exercise [8-11].

We hypothesised that this sequence of events would occur in $\mathrm{PAH}$ patients exhibiting reduced expiratory flows at low lung volumes at spirometry. To test this hypothesis, we examined the impact of exercise-induced increased ventilation on operating lung volumes in young nonsmoking, nonobstructive $\mathrm{PAH}$ patients. We also aimed to study the putative contribution of $\mathrm{DH}$ and the corresponding mechanical constraints on $V \mathrm{~T}$ expansion to exertional dyspnoea in this setting.

\section{MATERIAL AND METHODS Patients and controls}

We studied 25 nonsmoking consecutive clinically stable patients with idiopathic or heritable PAH [12], diagnosed according to the current evidence-based clinical practice guidelines [13, 14], with a normal body mass index (BMI) and no spirometric evidence of an obstructive ventilatory defect [15]. This sample size provides an $80 \%$ power to detect a significant difference (two-sided $\alpha=0.05$ ) in dyspnoea intensity (Borg scale) measured at a standardised work rate during incremental cycle cardiopulmonary exercise testing (CPET), based on a relevant difference in Borg ratings of $\sim 1.5$, a standard deviation of $\sim 1.0$ for Borg ratings changes having been found in our laboratory. Patients were included in the study irrespective of the treatment received, if they had been clinically stable during the three preceding months, and if they were scheduled for CPET within the frame of their clinical follow-up at the reference centre. A control group of 10 age-matched healthy subjects, all of them lifelong nonsmokers and having a normal spirometry [15], was taken from two previous studies [16, 17]. The research was carried out in accordance with the principles outlined in the Declaration of Helsinki. The subjects gave their informed consent to participate, and the study received the approval of the Institutional Review Board of the French learned society for respiratory medicine (Comité d'Evaluation des Protocoles de Recherche Observationnelle, Société de Pneumologie de Langue Française, CEPRO 2010-020). Please see the online supplementary material for more detail.

\section{Procedures}

Pulmonary function tests were performed according to recommended standards [18-20]. Measurements were expressed as percentages of predicted normal values [21]; predicted inspiratory capacity (IC) was calculated as predicted TLC minus predicted functional residual capacity. Procedures for conducting symptom-limited incremental CPET have been described previously $[8,9]$. The intensity of dyspnoea and of leg discomfort were rated using the modified 10-point Borg scale [22] at rest, every minute during exercise and at peak exercise. Inspiratory flow reserve, an indirect index of inspiratory muscle constraint/ fatigue, was assessed using the technique described by JOHNSON et al. [23]. See the online supplementary material for more detail.

\section{Indices of ventilatory constraint}

Operating lung volumes derived from IC manoeuvres were measured at rest, every second minute during exercise and at the end of exercise based on the assumption that TLC did not change significantly during the exercise. To ensure that this was actually the case, TLC was measured before and immediately after completion of CPET. DH was defined as any decrease in IC (expressed as absolute value or as percentage of TLC, i.e. IC/TLC (\%)) from rest to peak exercise, as previously described $[8,24]$. The ratios of inspiratory reserve volume (IRV) to TLC (IRV/TLC (\%)) and of $V$ T to IC (VT/IC (\%)) were both taken as indices of the mechanical constraint on $V \mathrm{~T}$ expansion [23].

\section{Statistical analysis}

Unless otherwise specified, variables are summarised as mean $\pm S D$. Statistical procedures were carried out using either Statview 5.0 (Abacus Concepts, San Francisco, CA, USA) or Prism 4.0 (GraphPad Software, Inc., San Diego, CA, USA). One-way ANOVA was used to assess differences in resting pulmonary function parameters between the control group, PAH patients who developed DH (PAH-H) and those who did not (PAH-NH). Comparisons between the PAH group as a whole and the control group, and between $\mathrm{PAH}-\mathrm{H}$ and $\mathrm{PAH}-$ $\mathrm{NH}$ (see results section for more detail) were performed at rest, at common standardised exercise work rates (WR) $(20 \mathrm{~W}$ : isoWR 1, and $60 \mathrm{~W}$; iso-WR 2), and at peak exercise using unpaired t-tests with appropriate Bonferroni adjustments for multiple comparisons. Pearson correlations were used to establish associations between Borg dyspnoea ratings at a standardised exercise WR (dependent variable) and concurrent relevant independent variables (i.e. exercise measurements of $V^{\prime} \mathrm{E}$, breathing pattern, operating lung volumes, cardiovascular and metabolic parameters, and baseline pulmonary function measurements). Differences were considered significant when the p-value of a type I error was $<0.05$.

\section{RESULTS}

The characteristics of the participants and their resting pulmonary function measurements are summarised in table 1. 20 patients were diagnosed with idiopathic PAH and five with heritable PAH. Seven patients were in functional class I according to the New York Heart Association (NYHA) classification, 13 in class II and five in class III. It is of note that all the patients had received PAH-specific pharmacotherapy according to guidelines $[13,14]$ and had been clinically stable during the three preceding months. PAH-specific pharmacotherapy is summarised in table S1.

\section{Physiological group responses to CPET}

The physiological and perceptual responses to CPET are summarised in table 2. Compared with the control subjects, $V^{\prime} \mathrm{E}$ was significantly increased at any submaximal WR in all PAH patients, whereas it was significantly reduced at peak exercise (fig. S1). When compared with controls, dyspnoea intensity was higher in the PAH group at any given WR and $V^{\prime}$ E (fig. 1). Dyspnoea/oxygen uptake $\left(V^{\prime} \mathrm{O}_{2}\right)$ and dyspnoea/ $V^{\prime}$ E slopes were also greater in the PAH patients than in the control subjects $(6.9 \pm 2.8$ and $0.12 \pm 0.04$ versus $2.0 \pm 1.0$ and $0.04 \pm 0.02$, respectively; $\mathrm{p}<0.05)$. $\mathrm{PAH}$ patients presented with a relatively rapid and shallow breathing pattern (fig. 1). IC increased in both patients and control subjects during the first $20 \mathrm{~W}$ of exercise; thereafter, IC decreased consistently only in $\mathrm{PAH}$ patients, while it continued to increase in healthy controls 


\begin{tabular}{|c|c|c|}
\hline \multirow[t]{2}{*}{ TABLE 1} & \multicolumn{2}{|c|}{$\begin{array}{l}\text { Anthropometric characteristics and resting } \\
\text { pulmonary function testing in pulmonary arterial } \\
\text { hypertension (PAH) patients and in controls }\end{array}$} \\
\hline & РАН & Controls \\
\hline Female/male n & $15 / 10$ & $5 / 5$ \\
\hline Age yrs & $38 \pm 12$ & $39 \pm 16$ \\
\hline Height $\mathrm{cm}$ & $168 \pm 8$ & $171 \pm 9$ \\
\hline $\mathrm{BMI} \mathbf{k g} \cdot \mathrm{m}^{-2}$ & $24 \pm 3$ & $23 \pm 4$ \\
\hline FEV1 L (\% pred) & $3.0 \pm 0.8^{*}(91 \pm 16)^{*}$ & $4.0 \pm 0.7(116 \pm 11)$ \\
\hline FVC L (\% pred) & $3.6 \pm 1.0^{*}(93 \pm 17)^{*}$ & $4.7 \pm 0.8(116 \pm 10)$ \\
\hline FEV $_{1} /$ VC $^{\#} \%$ & $115 \pm 10$ & $110 \pm 5$ \\
\hline TLC L (\% pred) & $5.3 \pm 1.1^{*}(93 \pm 10)^{*}$ & $6.4 \pm 0.9(107 \pm 9)$ \\
\hline VC L (\% pred) & $3.7 \pm 1.1^{\star}(94 \pm 17)^{\star}$ & $4.7 \pm 0.8(113 \pm 10)$ \\
\hline FRC L (\% pred) & $2.8 \pm 0.6(95 \pm 14)$ & $3.2 \pm 0.7(104 \pm 16)$ \\
\hline IC L (\% pred) & $2.5 \pm 0.8^{*}(93 \pm 20)^{*}$ & $3.2 \pm 0.4(108 \pm 18)$ \\
\hline RV L (\% pred) & $1.6 \pm 0.4(97 \pm 23)$ & $1.7 \pm 0.5(95 \pm 17)$ \\
\hline ERV L (\% pred) & $1.2 \pm 0.5(93 \pm 36)$ & $1.5 \pm 0.6(115 \pm 34)$ \\
\hline $\mathrm{FEF} 25 \% \mathrm{~L} \cdot \mathrm{s}^{-1}$ (\% pred) & $6.7 \pm 1.7(100 \pm 16)$ & $7.6 \pm 1.8(108 \pm 10)$ \\
\hline FEF50\% L.s ${ }^{-1}$ (\% pred) & $4.0 \pm 1.2^{*}(89 \pm 20)^{*}$ & $5.1 \pm 1.0(109 \pm 18)$ \\
\hline FEF75\% L.s ${ }^{-1}$ (\% pred) & $1.4 \pm 0.7^{*}(69 \pm 25)^{*}$ & $2.2 \pm 0.7(105 \pm 8)$ \\
\hline
\end{tabular}

Data are presented as mean $\pm \mathrm{SD}$, unless otherwise stated. BMI: body mass index; FEV1: forced expiratory volume in $1 \mathrm{~s}$; \% pred: \% predicted; FVC: forced vital capacity; TLC: total lung capacity; VC: vital capacity; FRC: functional residual capacity; IC: inspiratory capacity; RV: residual volume; ERV: expiratory reserve volume; FEF25\%, 50\% and $75 \%$ : forced expiratory flow at $25 \%, 50 \%$ and $75 \%$, respectively, of the FVC. \#: spirometric evidence of an obstructive ventilatory defect as defined by a reduced FEV1 NC ratio below the fifth percentile of the predicted value [15]. *: $p<0.05$, overall PAH versus healthy.

(table 2 and fig. 1). On average, the rest-to-peak IC change was $-0.15 \pm 0.46 \mathrm{~L}$ in $\mathrm{PAH}$ patients and $0.45 \pm 0.16 \mathrm{~L}$ in control subjects. The IRV/TLC (\%) and the $V \mathrm{~T} / \mathrm{IC}(\%)$ were significantly different in $\mathrm{PAH}$ patients than in control subjects at a given WR and $V^{\prime} E$ (table 2 and fig. 1).

\section{Identification of two subgroups of PAH patients}

Based on rest-to-peak changes in IC, 15 (60\%) PAH patients exhibited DH during exercise (PAH-H group, IC $-0.50 \pm 0.15 \mathrm{~L}$ ), whereas the remaining 10 patients did not (PAH-NH group, IC $+0.36 \pm 0.18 \mathrm{~L}$ ) (fig. 2). Both $\mathrm{PAH}-\mathrm{H}$ and $\mathrm{PAH}-\mathrm{NH}$ patients were stable on therapy with a satisfactory haemodynamic and clinical response, as demonstrated by cardiac output at rest, right atrial pressure, NYHA functional class and 6-min walk distance (table 3). Characteristics and pulmonary function tests at rest of the two groups are compared in table 3. PAH-H patients presented with reduced FEF75\% and expiratory reserve volume (ERV) at resting spirometry compared with PAH-NH (table 3). It is of note that TLC did not change after CPET, either in the $\mathrm{PAH}-\mathrm{H}$ group $(5.2 \pm 1.1$ versus $5.3 \pm 1.1 \mathrm{~L}$, respectively; $\mathrm{p}=0.4)$ or in the PAH-NH group $(5.6 \pm 1.1$ versus $5.6 \pm 1.0 \mathrm{~L}$, respectively; $\mathrm{p}=0.9$ ). The physiological and perceptual responses to CPET in the PAH-H and the PAH-NH groups are summarised in table 4. All metabolic and cardio-ventilatory measurements obtained at rest were similar in both groups, as were the patterns of $V^{\prime} \mathrm{O}_{2}$ and $V^{\prime} \mathrm{E}$ responses to exercise (iso-WR 1, iso-WR 2 and peak included) expressed relative to $\mathrm{WR}, V^{\prime} \mathrm{O}_{2}$ and carbon dioxide production $\left(V^{\prime} \mathrm{CO}_{2}\right)$ (table 4 and fig. 3). Response patterns were

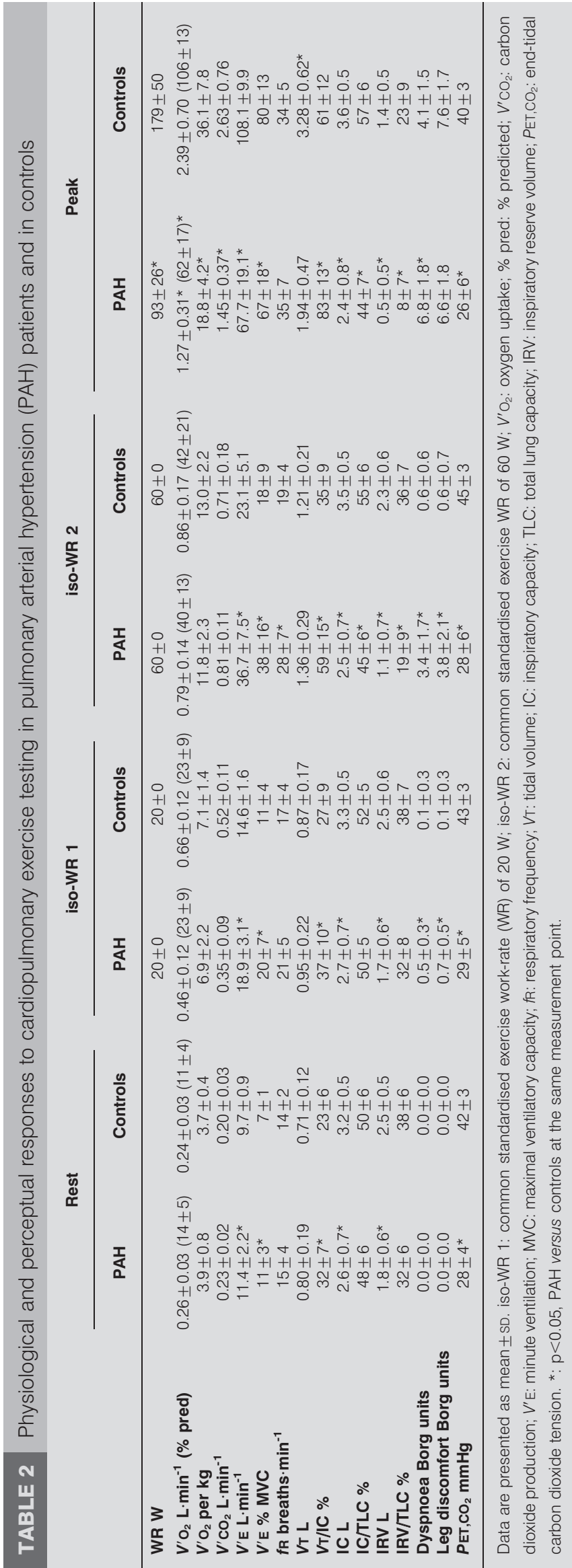



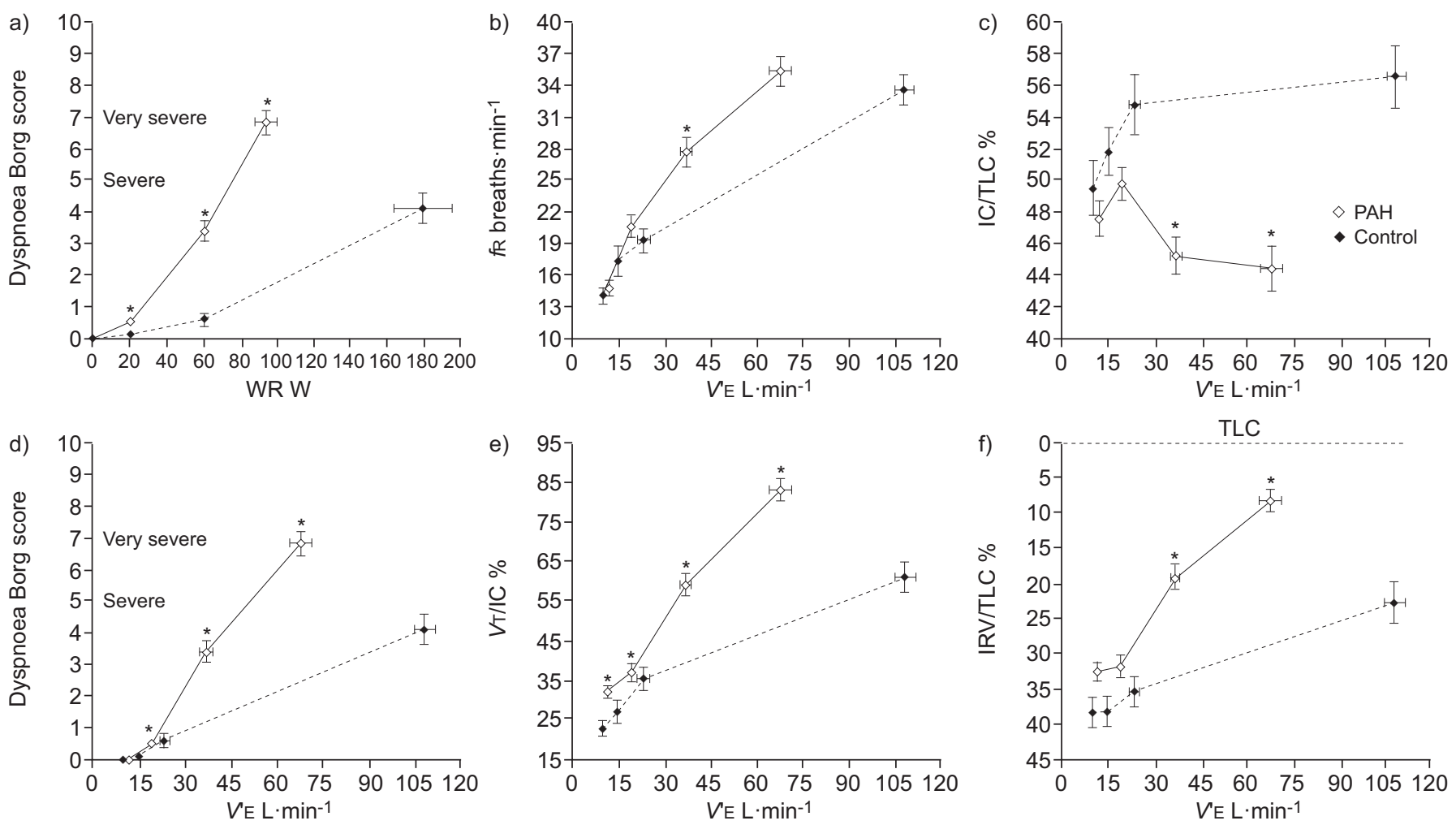

FIGURE 1. Exertional dyspnoea intensity (Borg score) is shown in response to increasing a) work rate (WR) and d) minute ventilation (V'E) during symptom-limited incremental cycle exercise in patients with pulmonary arterial hypertension (PAH) as whole group $(n=25)$ and in healthy control subjects $(n=10$; solid symbols and dash lines). b) Respiratory frequency (fR) and e) tidal volume (VT) expressed as percentage of inspiratory capacity (IC) (VT/IC (\%)) are shown in response to increasing V'E during symptom-limited incremental cycle exercise in patients with PAH as whole group and in healthy control subjects. c) IC and f) inspiratory reserve volume (IRV), both expressed as percentage of total lung capacity (TLC), are shown in response to increasing $V^{\prime} E$ during symptom-limited incremental cycle exercise in patients with PAH as whole group and in healthy control subjects. Restrictive constraints on VT expansion during exercise are significantly greater in the PAH group from both below (reduced IC) and above (reduced IRV) compared with healthy subjects. Data are presented as mean \pm SE values at rest, at $20 \mathrm{~W}$ (iso-WR 1), at $60 \mathrm{~W}$ (iso-WR 2) and at peak exercise. *: p<0.05, PAH versus healthy at rest, at common standardised exercise work-rates (20 W and $60 \mathrm{~W}$ ), or at peak exercise.

also similar when measurements of breathing pattern were plotted against $V^{\prime} E$ (fig. 3). In spite of these similarities, the dyspnoea $/ V^{\prime} \mathrm{O}_{2}$ and dyspnoea $/ V^{\prime} \mathrm{E}$ slopes were steeper in $\mathrm{PAH}-\mathrm{H}$ than in PAH-NH $(8.1 \pm 2.2$ and $0.14 \pm 0.04$ versus $5.1 \pm 2.7$ and $0.09 \pm 0.03$, respectively; $\mathrm{p}<0.05)$. Operating lung volumes were also different between the two groups throughout exercise. It is of note that IC increased in both PAH-H and $\mathrm{PAH}-\mathrm{NH}$ patients during the first $20 \mathrm{~W}$ of exercise; thereafter, IC decreased consistently only in $\mathrm{PAH}-\mathrm{H}$ patients while it continued to increase in PAH-NH patients (table 4 and fig. 2). Rest-to-60 W changes in IC/TLC did significantly differ between PAH-H and PAH-NH $(7.2 \pm 2$ versus $-5 \pm 3 \%$; $<<0.05)$. In addition, rest-to- $60 \mathrm{~W}$ changes in IRV/TLC (\%) were significantly different in PAH-H $(18 \pm 5 \%)$ than in $\mathrm{PAH}-\mathrm{NH}$ $(7 \pm 5 \% ; \mathrm{p}<0.05)$ (fig. 3$)$. Despite these differences in operating lung volume behaviour, inspiratory reserve flow at peak exercise was not statistically different between $\mathrm{PAH}-\mathrm{H}$ and PAH-NH (1.7 \pm 0.3 versus $\left.2.0 \pm 0.3 \mathrm{~L} \cdot \mathrm{s}^{-1} ; \mathrm{p}=0.6\right)$ (fig. 2). Finally, dyspnoea ratings were significantly greater in $\mathrm{PAH}-\mathrm{H}$ than in PAH-NH patients at a given WR and $V^{\prime} \mathrm{E}$ (table 4 and fig. 3 ).

\section{Correlates of exertional dyspnoea}

In the PAH patients taken as whole group $(n=25)$, the rest-to$60 \mathrm{~W}$ difference in Borg ratings of dyspnoea strongly correlated with the difference $(\Delta)$ in IC/TLC $(\%)(\mathrm{R}=-0.70,95 \% \mathrm{CI}$ $-0.857--0.422 ; \mathrm{p}<0.05)$ and the $\Delta \mathrm{IRV} / \mathrm{TLC}(\%)(\mathrm{R}=-0.78,95 \%$ CI $-0.897--0.555 ; \mathrm{p}<0.05)$. Therefore, $\sim 50-60 \%$ of the variance of difference in Borg ratings of dyspnoea was accounted for by changes in dynamic respiratory mechanics. It is of note that, as predicted from the COPD literature, the $\triangle \mathrm{IRV} / \mathrm{TLC}(\%)$ was strongly predicted by the $\triangle \mathrm{IC} / \mathrm{TLC}(\%)(\mathrm{R}=0.73,95 \% \mathrm{CI} 0.466-$ $0.871 ; \mathrm{p}<0.05)$. The difference in Borg ratings of dyspnoea also correlated with the $\Delta V^{\prime} \mathrm{E} /$ maximal ventilatory capacity (MVC) $(\%)(\mathrm{R}=0.59,95 \% \mathrm{CI} 0.257-0.799 ; \mathrm{p}<0.05)$. Change in dyspnoea intensity during exercise did not correlate with any of the other baseline pulmonary function variables or with any of the cardiovascular variables obtained during resting right heart catheterisation or with NYHA functional class.

\section{DISCUSSION}

The main findings of this study are as follows: 1) exertional dyspnoea ratings were higher at any given $\mathrm{WR}, V^{\prime} \mathrm{O}_{2}$ and $V^{\prime} \mathrm{E}$ in PAH patients compared with control subjects; 2 ) ventilatory abnormalities during exercise in $\mathrm{PAH}$ patients included a higher ventilatory demand, significant $\mathrm{DH}$, and a relatively rapid and shallow breathing pattern; 3) resting pulmonary function tests confirmed that the majority of $\mathrm{PAH}$ patients $(60 \%)$ exhibited reduced expiratory flows at low lung volumes; 

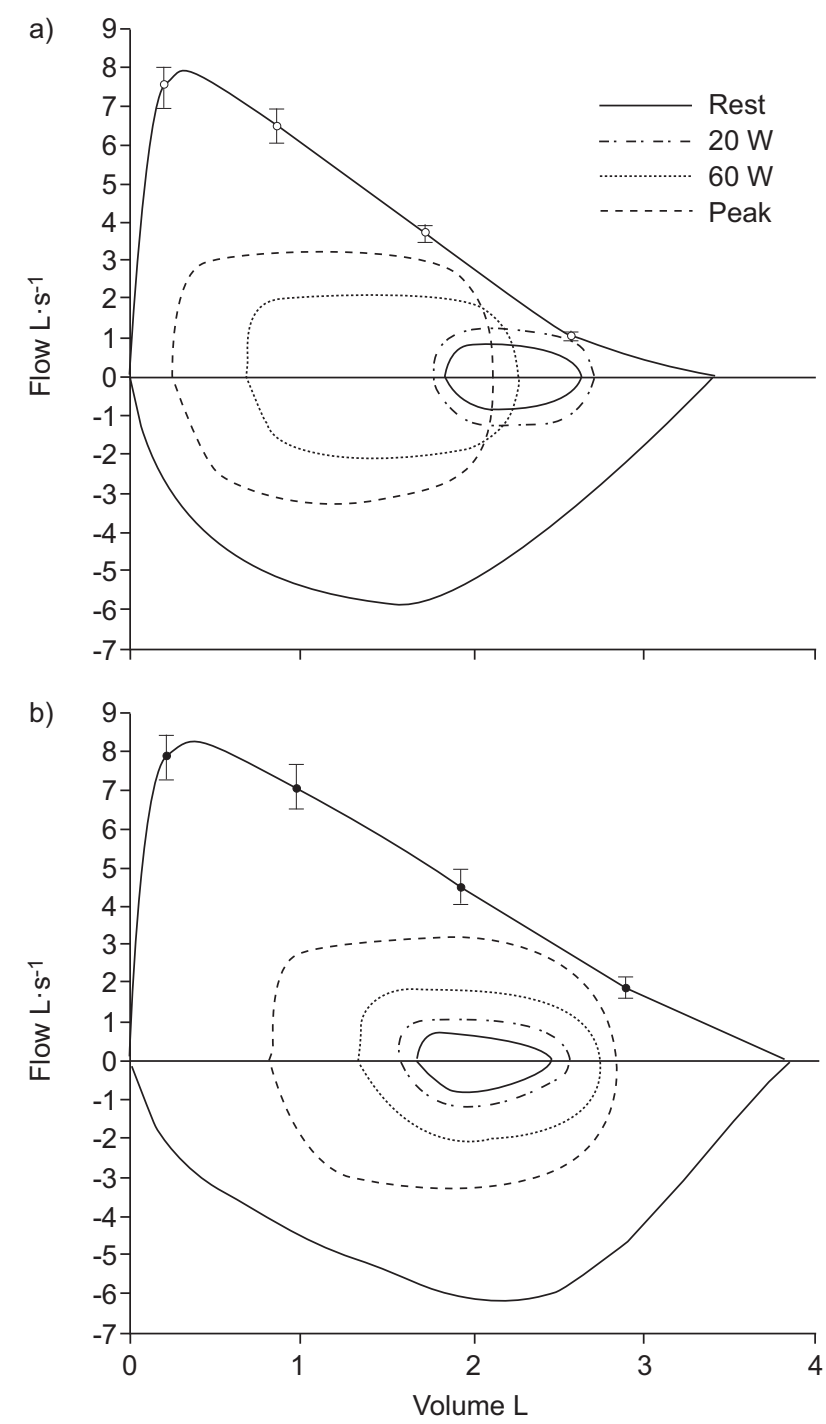

FIGURE 2. Maximal and tidal flow-volume loops (average data) are shown at rest and during incremental cycle exercise in patients with pulmonary arterial hypertension (PAH) a) with hyperinflation ( $\mathrm{PAH}-\mathrm{H} ; \mathrm{n}=15$, age $40 \pm 11 \mathrm{yrs}$ ) and b) without hyperinflation ( $\mathrm{PAH}-\mathrm{NH} ; \mathrm{n}=10$, age $35 \pm 13 \mathrm{yrs}$ ). Tidal flow-volume loops are provided at rest, early in exercise (at $20 \mathrm{~W}$ ), late in exercise (at $60 \mathrm{~W}$ ) and at peak exercise. Note a significant decrease in dynamic inspiratory capacity during exercise in $\mathrm{PAH}-\mathrm{H}$ compared with $\mathrm{PAH}-\mathrm{NH}$.

and 4) DH-related changes in operating lung volume (e.g. reduction of both IC/TLC and IRV/TLC) explained 50-60\% of the variance of difference in Borg ratings of dyspnoea during cycle exercise in patients with PAH.

The patients that we studied were young nonsmokers who suffered from idiopathic and heritable PAH. They had normal BMIs, no evidence of spirometric obstruction, and were stable on therapy with a satisfactory haemodynamic and clinical response, as demonstrated by cardiac output at rest, right atrial pressure, NYHA functional class and 6-min walk distance (table 3). These patients had mild-to-moderate exercise intolerance, with a peak symptom-limited $V^{\prime} \mathrm{O}_{2}$ being reduced by $23 \%$ on average of the predicted normal value (table 2 ), despite PAH-specific pharmacotherapy. We are satisfied that the reduced exercise performance in our PAH patients was not the result of reduced motivational effort: patients reported intolerable exertional symptoms at peak exercise and had a respiratory exchange ratio at peak $>1.15$.

During exercise, dyspnoea intensity ratings were higher at a given power output, whereas both dyspnoea $/ V^{\prime} \mathrm{O}_{2}$ and dyspnoea $/ V^{\prime} \mathrm{E}$ slopes were steeper in the PAH patients than in the control subjects. Similar or slightly lower levels of dyspnoea intensity have been reported in PAH patients with worse NYHA functional class than ours, but at much lower $V^{\prime} \mathrm{E}$ and WR [25]. Potential "respiratory" (as opposed to "cardiovascular") contributors to exertional dyspnoea in our PAH patients included: 1) greater abnormalities of dynamic ventilatory mechanics and muscle function that would cause dyspnoea to increase for any given $V^{\prime} E$ compared with health; 2) higher ventilatory drive/demand as a result of pulmonary gas exchange, deconditioning or cardio-metabolic abnormalities; or 3) a combination of both.

\section{Abnormal dynamic ventilatory mechanics}

Dyspnoea/ $V^{\prime}$ E slopes were consistently elevated during exercise in our PAH patients, suggesting increased intrinsic mechanical loading and/or functional weakness of the ventilatory muscles. Resting pulmonary function tests showed unambiguous mechanical abnormalities in 15 out of $25 \mathrm{PAH}$ patients (i.e. PAH-H). These patients exhibited a consistent and uniform reduction of the maximal expiratory flow rates over the effort-independent portion of the maximal flow-volume curve, whilst the FEV1/VC ratio, TLC, VC and IC were preserved. Whether these spirometric abnormalities truly reflect peripheral airways obstruction is still debated [5-7]. However, small airway dysfunction has previously been described in $\mathrm{PAH}[5,6]$; its mechanisms are poorly understood. They could include competition for space between hypertrophied vessels and distal airways within the interstitial space [26], small airway wall thickening, airway mucus plugs, airway hyperresponsiveness, the attendant effects of ageing or tobacco smoking, or various combinations of these factors [5]. In our study, we excluded elderly patients, as well as patients with a tobacco-smoking history, asthma and other cardio-respiratory diseases. In addition, the duration of the disease did not differ between $\mathrm{PAH}-\mathrm{H}$ and $\mathrm{PAH}-\mathrm{NH}$ patients. Pathological studies are needed to understand the differences in airway morphology between PAH patients who exhibit small airway dysfunction and PAH patients who do not.

Regardless of the mechanisms underlying the PAH-related small airway dysfunction, the reduced resting ERV and the shape and limits of the maximal flow-volume curve in the tidal operating range (showing a reduction of FEF75\%) mean that, in our PAH-H patients, the operating $V \mathrm{~T}$ was positioned closer to RV than normally. As a result, our PAH-H patients had an increased propensity to expiratory flow limitation. Indeed, although PAH-H patients did not exhibit expiratory flow limitation during resting breathing, they encroached on their maximal expiratory flow reserve relatively early in exercise (at $20 \mathrm{~W}$, fig. 2). In fact, our $\mathrm{PAH}-\mathrm{H}$ patients demonstrated an initial increase in IC (from rest to $20 \mathrm{~W}$ ) and they were able to accommodate their $V$ T within the ERV due to the available expiratory flow (reserve) at that lung volume (fig. 2). Under these circumstances, it is not surprising 


\begin{tabular}{|c|c|c|c|c|}
\hline TABLE 3 & \multicolumn{4}{|c|}{$\begin{array}{l}\text { Anthropometric characteristics, cardiovascular variables obtained during resting right heart catheterisation under } \\
\text { pharmacotherapy, and resting pulmonary function testing in pulmonary arterial hypertension (PAH) patients who } \\
\text { developed dynamic lung hyperinflation during exercise (PAH-H) and those who did not (PAH-NH), and in controls }\end{array}$} \\
\hline \multicolumn{2}{|l|}{ Subjects $\mathbf{n}$} & 15 & 10 & 10 \\
\hline \multicolumn{2}{|c|}{ Female/male $n$} & $9 / 6$ & $6 / 4$ & $5 / 5$ \\
\hline \multicolumn{2}{|l|}{ Height $\mathrm{cm}$} & $167 \pm 8$ & $169 \pm 9$ & $171 \pm 9$ \\
\hline \multicolumn{2}{|c|}{ Body mass index $\mathrm{kg} \cdot \mathrm{m}^{-2}$} & $25 \pm 3$ & $22 \pm 3$ & $23 \pm 4$ \\
\hline \multicolumn{2}{|c|}{ Duration of disease months } & $70 \pm 59$ & $79 \pm 78$ & \\
\hline \multicolumn{2}{|c|}{ NYHA functional class } & $2 \pm 1$ & $2 \pm 1$ & \\
\hline \multicolumn{2}{|c|}{ 6MWD m } & $523 \pm 84$ & $568 \pm 113$ & \\
\hline \multicolumn{2}{|c|}{ mPAP mmHg } & $48 \pm 13$ & $50 \pm 22$ & \\
\hline \multicolumn{2}{|c|}{$\mathrm{CI} \mathrm{L} \cdot \mathrm{min}^{-1} \cdot \mathrm{m}^{-2}$} & $3.7 \pm 0.6$ & $3.5 \pm 0.7$ & \\
\hline \multicolumn{2}{|c|}{ Mixed venous oxygen saturation \% } & $72 \pm 6$ & $71 \pm 6$ & \\
\hline \multicolumn{5}{|c|}{ Resting pulmonary function } \\
\hline \multicolumn{2}{|c|}{ FEV 1 L (\% pred) } & $2.8 \pm 0.7^{\circ}(88 \pm 17)^{\bullet}$ & $3.3 \pm 0.9(95 \pm 14)^{+}$ & $4.0 \pm 0.7(116 \pm 11)$ \\
\hline \multicolumn{2}{|c|}{ FVC L (\% pred) } & $3.4 \pm 1.0^{\circ}(91 \pm 17)^{\bullet}$ & $3.9 \pm 1.0(97 \pm 17)^{+}$ & $4.7 \pm 0.8(116 \pm 10)$ \\
\hline \multicolumn{2}{|c|}{$\mathrm{FEV}_{1} / \mathrm{NC}^{\#} \%$} & $113 \pm 11$ & $117 \pm 9$ & $110 \pm 5$ \\
\hline \multicolumn{2}{|c|}{ TLC L (\% pred) } & $5.2 \pm 1.1^{\circ}(92 \pm 11)^{\bullet}$ & $5.6 \pm 1.1(96 \pm 10)$ & $6.4 \pm 0.9(107 \pm 9)$ \\
\hline \multicolumn{2}{|c|}{ VC L (\% pred) } & $3.6 \pm 1.1^{\circ}(93 \pm 18)^{\circ}$ & $4.0 \pm 1.0(96 \pm 16)$ & $4.7 \pm 0.8(113 \pm 10)$ \\
\hline \multicolumn{2}{|c|}{ FRC L (\% pred) } & $2.6 \pm 0.5^{\bullet}(89 \pm 10)^{5,9}$ & $3.1 \pm 0.6(103 \pm 14)$ & $3.2 \pm 0.7(104 \pm 16)$ \\
\hline \multicolumn{2}{|c|}{ IC L (\% pred) } & $2.6 \pm 0.8(98 \pm 22)$ & $2.5 \pm 0.6(90 \pm 17)$ & $3.2 \pm 0.4(108 \pm 18)$ \\
\hline \multicolumn{2}{|c|}{ RV L (\% pred) } & $1.6 \pm 0.5(93 \pm 24)$ & $1.6 \pm 0.4(94 \pm 23)$ & $1.7 \pm 0.5(95 \pm 17)$ \\
\hline
\end{tabular}

Data are presented as mean $\pm \mathrm{SD}$, unless otherwise stated. NYHA: New York Heart Association; 6MWD: 6-min walking distance; mPAP: mean pulmonary artery pressure; Ppcw: pulmonary capillary wedge pressure; PVR: pulmonary vascular resistance; CO: cardiac output; Cl: cardiac index; FEV1: forced expiratory volume in $1 \mathrm{~s}$; \% pred: \% predicted; FVC: forced vital capacity; VC: vital capacity; TLC: total lung capacity; FRC: functional residual capacity; IC: inspiratory capacity; RV: residual volume; ERV: expiratory reserve volume; $\mathrm{FEF} 25 \%, 50 \%$ and $75 \%$ : forced expiratory flow at $25 \%, 50 \%$ and $75 \%$, respectively, of the FVC. $\mathrm{p}<0.05$ (one-way ANOVA): \#: spirometric evidence of an obstructive ventilatory defect as defined by a reduced FEV1 1 VC ratio below the fifth percentile of the predicted value [15]; ${ }^{\circ}$ : PAH-H versus controls; ${ }^{+}$: PAH-NH versus controls; ${ }^{\text {s: }}$ PAH-H versus PAH-NH.

that the rise of dyspnoea intensity was attenuated (table 4 and fig. 3). In contrast, from $20 \mathrm{~W}$ to peak exercise, the PAH-H patients were no more able to expand $V \mathrm{~T}$ by encroaching on the ERV due to the no longer available expiratory flow (reserve) at that lung volume. As a consequence, VT continued to increase only by encroaching on the IRV, and the IC decreased substantially $(\mathrm{DH})$ in $\mathrm{PAH}-\mathrm{H}$, under the condition of increased ventilatory demand. During the accelerated ventilatory response to exercise IC decreased by an average of $0.50 \mathrm{~L}$ from rest to peak exercise in PAH-H. Similar levels of $\mathrm{DH}$ have been reported in healthy subjects between 40 and 80 yrs of age [27], patients with mild-to-severe COPD [9-11], CHF [8, 28], and recently also by Richter et al. [29] in a heterogeneous group of patients with pre-capillary pulmonary hypertension, but at much lower $V^{\prime} E$ and WR than in our more homogeneous group of PAH patients. In addition, RICHTER et al. [29] did not describe the dual pattern of exercise-related lung volume changes that we observed in our patients. This duality, if corroborated in a large population, would be of importance regarding selection of patients for therapeutic interventions aimed at attenuating exercise-induced DH. In addition, they neither measured dyspnoea intensity nor related the ventilatory mechanics changes that they observed during exercise to dyspnoea [29].

What does the dynamic decrease in IC reflect in patients with PAH? As TLC remained stable throughout exercise, we can assume that the decrease in dynamic IC reflects an increase in the rate of change in EELV, i.e. DH. An alternative explanation would be a decreased inspiratory muscle performance [30, 31]. We cannot exclude a contribution of inspiratory muscle weakness or fatigue to the decreased IC in our patients, and to the concomitant alterations in breathing pattern. Indeed, respiratory muscle dysfunction has been suspected in $\mathrm{PAH}$ patients [30, 31], mostly in severely compromised PAH [32]. 
TABLE 4 Physiological and perceptual responses to cardiopulmonary exercise testing in pulmonary arterial hypertension (PAH) patients who developed dynamic lung hyperinflation during exercise (PAH-H) and those who did not (PAH-NH)

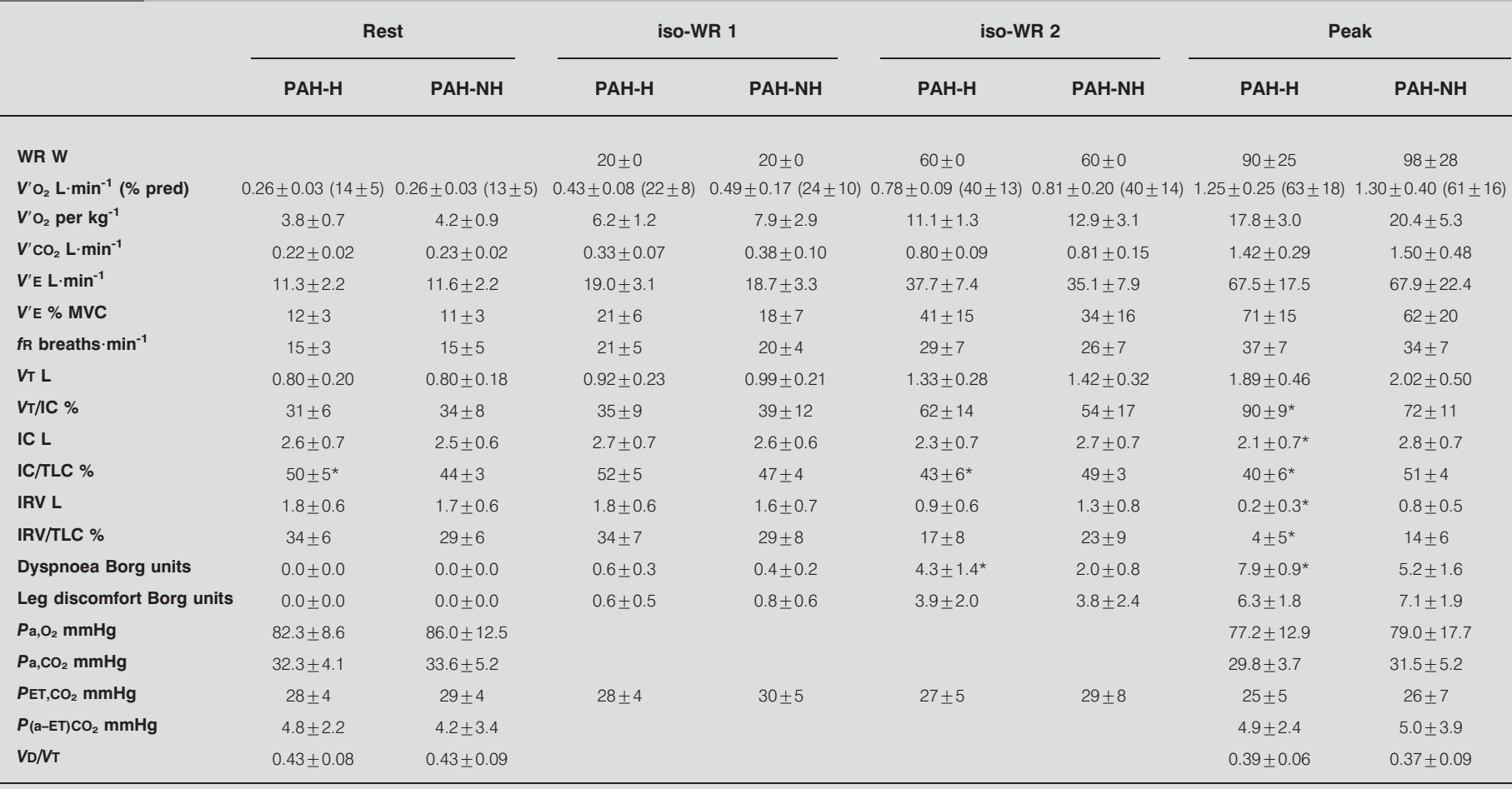

Data are presented as mean $\pm \mathrm{SD}$. iso-WR 1: common standardised exercise work-rate (WR) of $20 \mathrm{~W}$; iso-WR 2: common standardised exercise WR of $60 \mathrm{~W}$; $V^{\prime} \mathrm{O}_{2}$ : oxygen uptake; \% pred: \% predicted; $V^{\prime} \mathrm{CO}_{2}$ : carbon dioxide production; $V^{\prime} E$ : minute ventilation; MVC: maximal ventilatory capacity; fR: respiratory frequency; $V T$ : tidal volume; IC: inspiratory capacity; TLC: total lung capacity; IRV: inspiratory reserve volume; $\mathrm{Pa}_{2} \mathrm{O}_{2}$ : arterial oxygen tension; $\mathrm{Pa}_{\mathrm{a}} \mathrm{CO}_{2}$ : arterial carbon dioxide tension; $\mathrm{PET}, \mathrm{CO}_{2}$ : end-tidal carbon dioxide tension; $\mathrm{P}(\mathrm{a}-\mathrm{ET}) \mathrm{CO}_{2}$ : the gradient between arterial and end-tidal carbon dioxide tension; VD: physiological dead space. ${ }^{*}: \mathrm{p}<0.05, \mathrm{PAH}-\mathrm{H}$ versus $\mathrm{PAH}-\mathrm{NH}$ at the same measurement point

However, both PAH-H and PAH-NH patients achieved inspiratory tidal flows that approached a similar percentage of the maximal available inspiratory flows (i.e. similar inspiratory flow reserve), suggesting that the inspiratory flow-generating reserve of the inspiratory muscles at peak exercise was similar (but occurred at different operating lung volumes), thus making the presence of inspiratory muscle constraint/fatigue unlikely. If this was indeed the case, IC would have decreased in PAH patients who did not actually develop DH during exercise as much as in those who did develop DH on exertion. Therefore, it is unlikely that $\mathrm{PAH}-\mathrm{H}$ patients did suffer from an impairment of inspiratory muscle strength that would have been sufficient to prevent them from reaching TLC during a voluntary manoeuvre. PAH-H patients were similar to the $\mathrm{PAH}-\mathrm{NH}$ patients regarding their general characteristics, the severity, the duration and the medical management of the disease.

Irrespective of its cause, the rapid development of DH during exercise observed in our $\mathrm{PAH}-\mathrm{H}$ patients is likely to have a sensory consequence, as clearly reported in patients with various cardiorespiratory diseases [8-11]. DH causes increased elastic loading and functional weakness of the inspiratory muscles, thus imposing severe mechanical constraints on $V \mathrm{~T}$ expansion during exercise on a background of progressively increasing central neural drive $[8,9,33]$ : $V \mathrm{~T}$ is truncated from below by the increasing EELV and constrained from above by the TLC envelope and the relatively reduced IRV. Thus, compared with age-matched $\mathrm{PAH}-\mathrm{NH}, \mathrm{PAH}-\mathrm{H}$ patients at comparable WR and $V^{\prime} E$ showed substantially greater increases in dynamic EELV, a greater ratio of $V \mathrm{~T}$ to $\mathrm{IC}$, and marked reduction in the IRV. Although PAH patients (either all together or as $\mathrm{PAH}-\mathrm{H}$ or $\mathrm{PAH}-\mathrm{NH}$ ) did not show a ventilatory limitation during exercise as traditionally determined by the ratio of $V^{\prime} \mathrm{E}$ to MVC exceeding at least $85 \%$ [23, 34], significant ventilatory constraints and the attendant respiratory difficulty were evident in the majority of $\mathrm{PAH}$ patients. This has been well documented in patients with COPD and CHF during exercise $[8,11,35]$. It is generally accepted that, in this setting, dyspnoea results from the conscious awareness of the growing disparity between increased respiratory effort (or neural drive to breathe) and the simultaneous blunted thoracic volume displacement. We argue that this was the case in our $\mathrm{PAH}-\mathrm{H}$ patients and, therefore, that the dyspnoea they reported was at least in part due to altered respiratory mechanics [33]. Indeed, at standardised WRs, dyspnoea intensity was significantly higher and dynamic IRV was proportionately lower in the PAH-H group than in the PAH-NH group and in the control subjects. The notion that DH and the subsequent constraint of $V \mathrm{~T}$ expansion contributed to exertional dyspnoea is bolstered by the strong inverse correlation between dyspnoea intensity and both the reduced dynamic IC/TLC $(\%)(R=-0.70 ; p<0.05)$ and the IRV/TLC $(\%)(R=-0.78$; $\mathrm{p}<0.05)$ at a standardised exercise stimulus. However, we are 

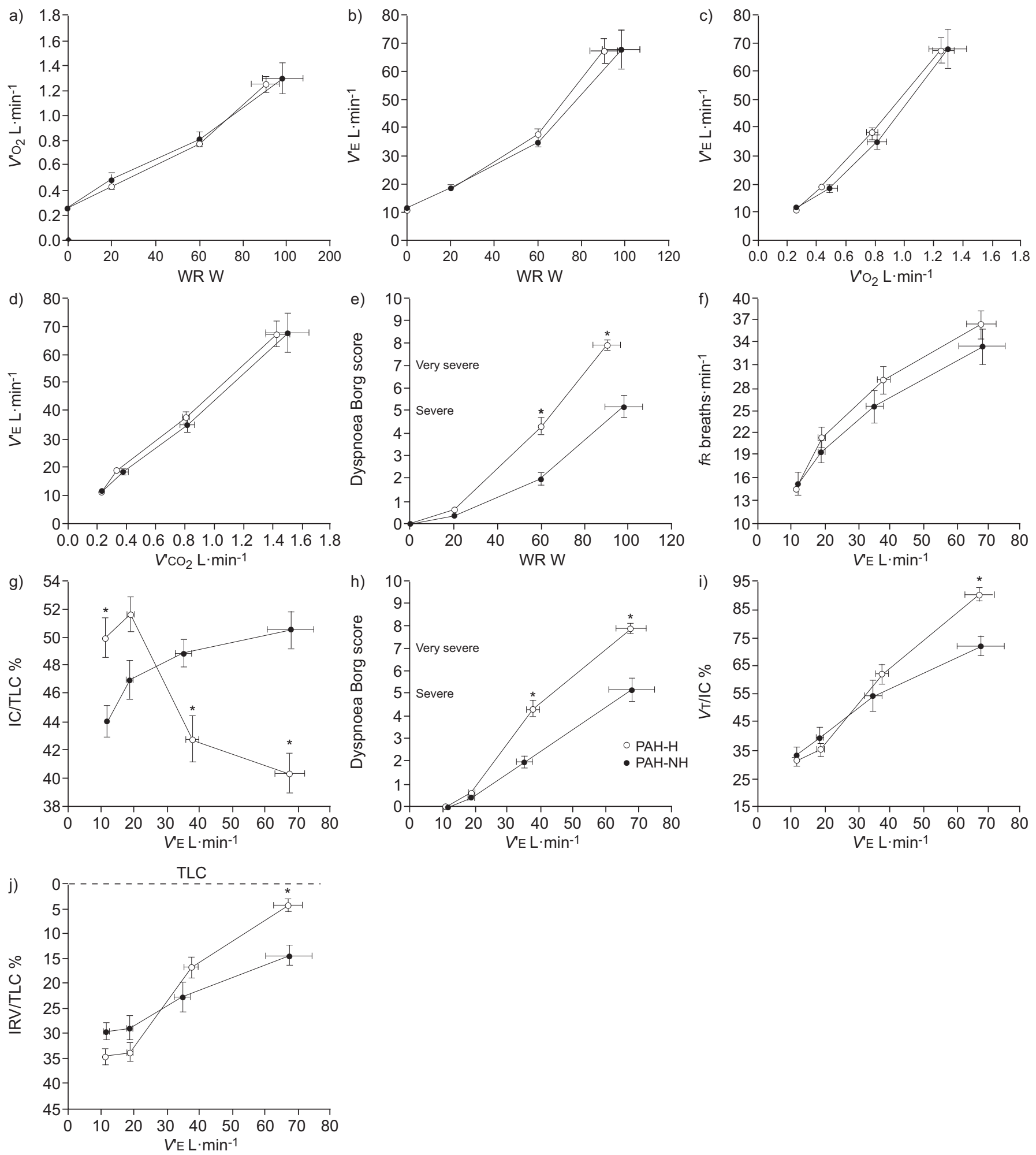

FIGURE 3. a) Oxygen uptake $\left(V^{\prime} \mathrm{O}_{2}\right)$ and b) minute ventilation $\left(V^{\prime} E\right)$ are shown in response to increasing work rate (WR) during symptom-limited incremental cycle exercise in patients with pulmonary arterial hypertension with hyperinflation $(\mathrm{PAH}-\mathrm{H})(\mathrm{n}=15)$, and in those without hyperinflation $(\mathrm{PAH}-\mathrm{NH})(\mathrm{n}=10)$. $V^{\prime} \mathrm{E}$ is shown in response to c) increasing $\mathrm{V}^{\prime} \mathrm{O}_{2}$ and d) carbon dioxide production $\left(\mathrm{V}^{\prime} \mathrm{CO}_{2}\right)$ during symptom-limited incremental cycle exercise in PAH-H and PAH-NH patients. Exertional dyspnoea intensity (Borg score) is shown in response to e) increasing WR and h) $V^{\prime} E$ during symptom-limited incremental cycle exercise in PAH-H patients and in PAH-NH patients. f) respiratory frequency ( $(R)$ and i) tidal volume ( $V T$ ) expressed as percentage of inspiratory capacity (IC) are shown in response to increasing $V^{\prime} E$ during symptom-limited incremental cycle exercise in PAH-H and in PAH-NH. g) IC and j) inspiratory reserve volume (IRV) expressed as a percentage of total lung capacity (TLC) are shown in response to increasing $V^{\prime}$ E during symptom-limited incremental cycle exercise in PAH-H and in PAH-NH. Data are presented as mean \pm SE values at rest, at 20 W (iso-WR 1), at 60 W (iso-WR 2) and at peak exercise. ${ }^{*}: \mathrm{p}<0.05$, PAH-H versus PAH-NH at rest, at common standardised exercise WRs (20 W and $60 \mathrm{~W}$ ), or at peak exercise. 
aware that correlation does not necessarily imply causation and that other mechanisms (e.g. psychological aspects) may play a role in the dyspnoea perception. Further study is required to conclusively determine this.

\section{Increased ventilatory demand}

Our findings of an increased ventilatory demand during cycle exercise in PAH patients confirm previously published studies $[2,36]$. Briefly, peak $V^{\prime} \mathrm{E}$ was diminished, reflecting the reduced peak symptom-limited $V^{\prime} \mathrm{O}_{2}$. Compared with control subjects, $V^{\prime} \mathrm{E}$ was significantly increased in $\mathrm{PAH}$ patients at any given submaximal WR and $V^{\prime} \mathrm{O}_{2}$. The mechanisms of the excessive ventilatory response to exercise were beyond the objectives of the present study and were not, therefore, fully elucidated. Nevertheless, it is conceivable that a combination of reduced oxygen delivery/utilisation, deconditioning and ventilation/ perfusion abnormalities stimulated $V^{\prime} \mathrm{E}$ during exercise to a greater extent in $\mathrm{PAH}$ patients than in control subjects, as suggested by: 1) the greater $V^{\prime} \mathrm{E} / V^{\prime} \mathrm{CO}_{2}$ (slopes and ratios) and $V^{\prime} \mathrm{E} / V^{\prime} \mathrm{O}_{2} ; 2$ ) the greater dead space-to-tidal volume ratio (in the presence of low arterial carbon dioxide tension $\left(\mathrm{Pa}_{\mathrm{a}} \mathrm{CO}_{2}\right)$ that did not significantly fall further during exercise in PAH patients); 3) the earlier occurrence of anaerobic ventilatory thresholds (data not shown); 4) the greater cardiac frequency $/ V^{\prime} \mathrm{O}_{2}$ slopes (data not shown); and 5) the lower $V^{\prime} \mathrm{O}_{2} /$ cardiac frequency (i.e. oxygen pulse, data not shown) observed throughout exercise in PAH patients compared with healthy subjects. In addition, excessive ventilation in $\mathrm{PAH}$ can be due to alveolar hyperventilation due to a decreased $P a, C_{2}$ set point [2]. This set point has been shown to be affected by: 1) metabolic acidosis due to an impaired stroke volume response to exercise [37, 38]; 2) exerciseinduced hypoxaemia; 3) sympathetic over stimulation [39]; and 4) increased stimulation of blood pressure-responsive receptors in the pulmonary vasculature. Our data provide no insight into the relative contributions of these different factors in the excessive exercise ventilation in $\mathrm{PAH}$.

Regardless of the mechanism, the increased $V^{\prime} \mathrm{E}$ is likely to have contributed, in the presence of reduced expiratory flows at low lung volumes at spirometry, to the accelerated decrease in IC and to the greater dyspnoea intensity. A correlative analysis confirmed an association between dyspnoea intensity ratings and the $V^{\prime} \mathrm{E} / \mathrm{MVC}(\%)(\mathrm{R}=0.59 ; \mathrm{p}<0.05)$. The higher $V^{\prime} \mathrm{E}$ in $\mathrm{PAH}$ ultimately reflects a relatively increased central neural drive and contractile muscular effort (relative to the maximal possible value) for the ventilatory muscles.

\section{Limitations}

In the absence of oesophageal pressure measurements in this study, a choice justified by the exploratory nature of the study and our concern to keep it as close to observational as possible, we must concede that the decrease in dynamic IC may be due either to $\mathrm{DH}$, inspiratory muscle weakness or fatigue, or both in combination. Regardless of the mechanism, the consistent decrease in dynamic IC seen in PAH-H is likely to be physiologically and clinically meaningful. Given the small sample size, we must be careful to avoid any generalisation of our findings to the larger PAH population. Further studies with a larger sample size and engaging oesophageal pressure measurements during exercise will be required to definitively elucidate the physiological mechanisms of the altered ventilatory mechanics seen in PAH patients.

\section{Conclusions}

This study is the first to examine the impact of potential DHinduced critical mechanical constraints on the intensity of dyspnoea in young nonsmoking patients with idiopathic and heritable PAH undergoing symptom-limited incremental CPET. It confirms that reduced expiratory flows at low lung volumes at spirometry exist in a certain proportion of idiopathic and heritable PAH patients $(60 \%)$ despite a preserved FEV1/VC ratio. It demonstrates that these abnormalities promote $\mathrm{DH}$ in response to the exercise-related increase in ventilation that can be magnified by ventilation/perfusion mismatching and other factors. Although exercise-related dyspnoea in $\mathrm{PAH}$ has important cardiovascular determinants [2-4], our results indicate that abnormal dynamic ventilatory mechanics can contribute to the build-up of this symptom during exercise. It is of note that the changes in operating lung volumes that we observed (e.g. reduction of both IC/TLC and IRV/TLC) explained $50-60 \%$ of the variance of the exercise-related increase in dyspnoea. This could be considered surprising given the magnitude of these changes, but probably reflects the fact that adding a mechanical burden on top of cardiovascular limitations has an exponential effect on dyspnoea. The corollary of this is that therapeutic interventions aimed at reducing or delaying the DH-related mechanical constraints could possibly be useful add-ons to vasodilators in the management of $\mathrm{PAH}$ patients exhibiting reduced expiratory flows at low lung volumes. The present data are, however, not sufficient to reach this conclusion. Future studies will be needed to determine the exact indications and risk-benefit balance of such interventions, including bronchodilators, in the setting of PAH.

\section{SUPPORT STATEMENT}

P. Laveneziana was supported by: 1) the Seventh Framework Programme of the European Union, Support for training and career development of researchers (Marie Curie), International Re-integration Grants (IRG), FP7-PEOPLE-2010-RG, grant number PIRG07-GA-2010268396-EDPAH; and 2) PFIZER Investigator-Initiated Research (IIR), Grant number WS 942458.

\section{STATEMENT OF INTEREST}

Statements of interest for P. Laveneziana, O. Sitbon, G. Simonneau, M. Humbert and T. Similowski can be found at www.erj.ersjournals.com/ site/misc/statements.xhtml

\section{ACKNOWLEDGEMENTS}

The authors are grateful to C. Straus (Univ Paris 06, Equipe de Recherche ER 10 UPMC, Laboratoire de Physio-Pathologie Respiratoire, Faculté de Médecine Pierre et Marie Curie (site PitiéSalpêtrière), Paris, France) for his help in setting up the study and input to the manuscript; to A. Féré, C. Thomas, N. Mecreant and T. Rouyer (Service des Explorations Fonctionnelles Respiratoires, Hôpital Antoine Béclère, Clamart, France) for providing their technical assistance in conducting pulmonary function and cardiopulmonary exercise testings; and to X. Jaïs, L. Savale and D. Montani (Service de Pneumologie et Réanimation Respiratoire, Centre National de Référence de l'Hypertension Pulmonaire Sévère, Hôpital Antoine Béclère, Clamart, France) for recruiting the patients.

\section{REFERENCES}

1 McLaughlin VV, Badesch DB, Delcroix M, et al. End points and clinical trial design in pulmonary arterial hypertension. J Am Coll Cardiol 2009; 54: S97-S107. 
2 Sun XG, Hansen JE, Oudiz RJ, et al. Exercise pathophysiology in patients with primary pulmonary hypertension. Circulation 2001; 104: 429-435.

3 Arena R, Guazzi M, Myers J, et al. Cardiopulmonary exercise testing in the assessment of pulmonary hypertension. Expert Rev Respir Med 2011; 5: 281-293.

4 Sajkov D, Petrovsky N, Palange P. Management of dyspnea in advanced pulmonary arterial hypertension. Curr Opin Support Palliat Care 2010; 4: 76-84.

5 Fernandez-Bonetti P, Lupi-Herrera E, Martinez-Guerra ML, et al. Peripheral airways obstruction in idiopathic pulmonary artery hypertension (primary). Chest 1983; 83: 732-738.

6 Meyer FJ, Ewert R, Hoeper MM, et al. Peripheral airway obstruction in primary pulmonary hypertension. Thorax 2002; 57: 473-476.

7 Spiekerkoetter E, Fabel H, Hoeper MM. Effects of inhaled salbutamol in primary pulmonary hypertension. Eur Respir $J$ 2002; 20: 524-528.

8 Laveneziana P, O'Donnell DE, Ofir D, et al. Effect of biventricular pacing on ventilatory and perceptual responses to exercise in patients with stable chronic heart failure. J Appl Physiol 2009; 106: 1574-1583.

9 Laveneziana P, Webb KA, Ora J, et al. Evolution of dyspnea during exercise in chronic obstructive pulmonary disease: impact of critical volume constraints. Am J Respir Crit Care Med 2011; 184: 1367-1373.

10 O'Donnell DE, Revill SM, Webb KA. Dynamic hyperinflation and exercise intolerance in chronic obstructive pulmonary disease. Am J Respir Crit Care Med 2001; 164: 770-777.

11 Ofir D, Laveneziana $\mathrm{P}$, Webb KA, et al. Mechanisms of dyspnea during cycle exercise in symptomatic patients with GOLD stage I chronic obstructive pulmonary disease. Am J Respir Crit Care Med 2008; 177: 622-629.

12 Simonneau G, Robbins IM, Beghetti M, et al. Updated clinical classification of pulmonary hypertension. J Am Coll Cardiol 2009; 54: S43-S54.

13 Badesch DB, Champion HC, Sanchez MA, et al. Diagnosis and assessment of pulmonary arterial hypertension. J Am Coll Cardiol 2009; 54: S55-S66.

14 Galie N, Hoeper MM, Humbert M, et al. Guidelines for the diagnosis and treatment of pulmonary hypertension. Eur Respir $J$ 2009; 34: 1219-1263.

15 Pellegrino R, Viegi G, Brusasco V, et al. Interpretative strategies for lung function tests. Eur Respir J 2005; 26: 948-968.

16 Laveneziana P, Galarducci A, Binazzi B, et al. Inhaled furosemide does not alleviate respiratory effort during flow-limited exercise in healthy subjects. Pulm Pharmacol Ther 2008; 21: 196-200.

17 Duranti R, Bonetti L, Vivoli P, et al. Dyspnea during exercise in hyperbaric conditions. Med Sci Sports Exerc 2006; 38: 1932-1938.

18 Miller MR, Hankinson J, Brusasco V, et al. Standardisation of spirometry. Eur Respir J 2005; 26: 319-338.

19 Wanger J, Clausen JL, Coates A, et al. Standardisation of the measurement of lung volumes. Eur Respir J 2005; 26: 511-522.

20 Macintyre N, Crapo RO, Viegi G, et al. Standardisation of the single-breath determination of carbon monoxide uptake in the lung. Eur Respir J 2005; 26: 720-735.

21 Quanjer PH, Tammeling GJ, Cotes JE, et al. Lung volumes and forced ventilatory flows. Report Working Party Standardization of
Lung Function Tests, European Community for Steel and Coal. Official Statement of the European Respiratory Society. Eur Respir J Suppl 1993; 16: 5-40.

22 Borg GA. Psychophysical bases of perceived exertion. Med Sci Sports Exerc 1982; 14: 377-381.

23 Johnson BD, Weisman IM, Zeballos RJ, et al. Emerging concepts in the evaluation of ventilatory limitation during exercise: the exercise tidal flow-volume loop. Chest 1999; 116: 488-503.

24 Laveneziana P, Valli G, Onorati P, et al. Effect of heliox on heart rate kinetics and dynamic hyperinflation during high-intensity exercise in COPD. Eur J Appl Physiol 2011; 111: 225-234.

25 Deboeck G, Niset G, Lamotte M, et al. Exercise testing in pulmonary arterial hypertension and in chronic heart failure. Eur Respir J 2004; 23: 747-751.

26 Achouh L, Montani D, Garcia G, et al. Pulmonary arterial hypertension masquerading as severe refractory asthma. Eur Respir J 2008; 32: 513-516.

27 Ofir D, Laveneziana P, Webb KA, et al. Sex differences in the perceived intensity of breathlessness during exercise with advancing age. J Appl Physiol 2008; 104: 1583-1593.

28 O'Donnell DE, D'Arsigny C, Raj S, et al. Ventilatory assistance improves exercise endurance in stable congestive heart failure. Am J Respir Crit Care Med 1999; 160: 1804-1811.

29 Richter MJ, Voswinckel R, Tiede H, et al. Dynamic hyperinflation during exercise in patients with precapillary pulmonary hypertension. Respir Med 2012; 106: 308-313.

30 Meyer FJ, Lossnitzer D, Kristen AV, et al. Respiratory muscle dysfunction in idiopathic pulmonary arterial hypertension. Eur Respir J 2005; 25: 125-130.

31 Kabitz HJ, Schwoerer A, Bremer HC, et al. Impairment of respiratory muscle function in pulmonary hypertension. Clin Sci (Lond) 2008; 114: 165-171.

32 de Man FS, van Hees HW, Handoko ML, et al. Diaphragm muscle fiber weakness in pulmonary hypertension. Am J Respir Crit Care Med 2011; 183: 1411-1418.

33 Parshall MB, Schwartzstein RM, Adams L, et al. An Official American Thoracic Society Statement: Update on the Mechanisms, Assessment, and Management of Dyspnea. Am J Respir Crit Care Med 2012; 185: 435-452.

34 Palange $\mathrm{P}$, Ward SA, Carlsen $\mathrm{KH}$, et al. Recommendations on the use of exercise testing in clinical practice. Eur Respir J 2007; 29: 185-209.

35 Johnson BD, Beck KC, Olson LJ, et al. Ventilatory constraints during exercise in patients with chronic heart failure. Chest 2000; 117: 321-332.

36 Sun XG, Hansen JE, Oudiz RJ, et al. Pulmonary function in primary pulmonary hypertension. J Am Coll Cardiol 2003; 41: 1028-1035.

37 Holverda S, Gan CT, Marcus JT, et al. Impaired stroke volume response to exercise in pulmonary arterial hypertension. J Am Coll Cardiol 2006; 47: 1732-1733.

38 Wasserman K, Whipp BJ, Koyal SN, et al. Effect of carotid body resection on ventilatory and acid-base control during exercise. J Appl Physiol 1975; 39: 354-358.

39 Velez-Roa S, Ciarka A, Najem B, et al. Increased sympathetic nerve activity in pulmonary artery hypertension. Circulation 2004; 110: 1308-1312. 